\title{
Microfossils of Cyanobacteria in Carbonaceous Meteorites
}

\author{
Richard B. Hoover ${ }^{1}$ \\ Astrobiology Laboratory, \\ NASA/Marshall Space Flight Center, \\ National Space Science and Technology Center, \\ 320 Sparkman Dr., Huntsville, AL 35805 USA
}

\begin{abstract}
During the past decade, Environmental and Field Emission Scanning Electron Microscopes have been used at the NASA/Marshall Space Flight Center to investigate freshly fractured interior surfaces of a large number of different types of meteorites. Large, complex, microfossils with clearly recognizable biological affinities have been found embedded in several carbonaceous meteorites. Similar forms were notably absent in all stony and nickel-iron meteorites investigated. The forms encountered are consistent in size and morphology with morphotypes of known genera of Cyanobacteria and microorganisms that are typically encountered in associated benthic prokaryotic mats. Even though many coccoidal and isodiametric filamentous cyanobacteria have a strong morphological convergence with some other spherical and filamentous bacteria and algae, many genera of heteropolar cyanobacteria have distinctive apical and basal regions and cellular differentiation that makes it possible to unambiguously recognize the forms based entirely upon cellular dimensions, filament size and distinctive morphological characteristics. For almost two centuries, these morphological characteristics have historically provided the basis for the systematics and taxonomy of cyanobacteria. This paper presents ESEM and FESEM images of embedded filaments and thick mats found in-situ in the Murchison CM2 and Orgueil CI1 carbonaceous meteorites. Comparative images are also provided for known genera and species of cyanobacteria and other microbial extremophiles. Energy Dispersive X-ray Spectroscopy (EDS) studies indicate that the meteorite filaments typically exhibit dramatic chemical differentiation with distinctive difference between the possible microfossil and the meteorite matrix in the immediate proximity. Chemical differentiation is also observed within these microstructures with many of the permineralized filaments enveloped within electron transparent carbonaceous sheaths. Elemental distributions of these embedded filaments are not consistent with recent cyanobacteria or other living or preserved microbial extremophiles that have been investigated during this research. The meteorite filaments often have nitrogen content below the sensitivity level of the EDS detector. Carbon, Sulphur, Iron or Silicon are often highly enriched and hence anomalous $\mathrm{C} / \mathrm{N}$ and $\mathrm{C} / \mathrm{S}$ ratios when compared with modern cyanobacteria. The meteorite forms that are unambiguously recognizable as biological filaments are interpreted as indigenous microfossils analogous to several known genera of modern cyanobacteria and associated trichomic filamentous prokaryotes.
\end{abstract}

KEYWORDS: Microfossils, Carbonaceous Meteorites, Orgueil, Murchison, Energy Dispersive X-Ray Spectroscopy, Biomarkers, Biogenic Elements, Elemental Ratios, Cyanobacteria, Extremophiles

\section{INTRODUCTION}

In August, 1996, David McKay and co-workers announced the discovery of possible nanofossils in close association with a suite of biomarkers (PAHs, carbonate globules, and biogenic magnetite grains) and in the Mars meteorite ALH84001 (McKay et al., 1996). These convergent independent lines of evidence led to the interpretation of these forms as providing evidence for relic biogenic activity on ancient Mars. This interpretation has been vigorously challenged. It has been argued that these forms are too small for autonomous life forms and too simple as to be conclusively recognized as unambiguously biological in origin. They have been dismissed as either coating artifacts,

${ }^{1}$ E-mail: Richard.Hoover@NASA.GOV 
edges of crystals or mineral weathering products (i.e. not biogenic) or as recent microbial contaminants. Even though the ALH84001 nanofossils have failed to gain wide acceptance, this pioneering paper has had a profound and positive influence. It stimulated research into Astrobiology, Bacterial Paleontology and the exploration of microbial extremophiles and the limits of life. The ALH84001 meteorite results generated renewed interest in the investigation of chemical, mineral and morphological biomarkers and microfossils in terrestrial rocks, meteorites, and other astromaterials. In late 1996, shortly after the Mars meteorite results were announced, the search for evidence for microfossils in carbonaceous meteorites was initiated by the author at the NASA/Marshall Space Flight Center. ${ }^{2}$ An independent search for microfossils in carbonaceous meteorites had also been carried out by Alexei Yu. Rozanov and his colleagues at the Paleontological Institute, Russian Academy of Sciences in Moscow, Russia. ${ }^{3}$

In recognition of the criticisms that had been lodged against the ALH84001 nanofossils, rigorous protocols were instigated to make certain that similar problems would not be encountered. To insure that coating artifacts could not be interpreted as possible microfossils, all of the initial research was carried out on uncoated samples. Great care was taken to protect the surfaces under investigation from any possible contamination effects. The initial study was restricted to freshly fractured interior surfaces of the meteorites. Out of concern that the meteorite's exterior surface might have become contaminated with recent bacteria, fungi, pollen grains or other biological materials, the meteorite fusion crust was carefully avoided.

\section{INSTRUMENTS AND METHODS}

A wide variety of terrestrial rocks and meteorites as well as living cyanobacteria and other microbial extremophiles and modern and ancient biological materials and known fossils were studied at the NASA/Marshall Space Flight Center. These investigations used the Environmental and Field Emission Scanning Electron Microscopes (ESEM and FESEM) with both Secondary (SED) and Backscattered Electron (BSED) detectors. Visible Light (Bright Field, Dark Field and Phase Contrast) studies for comparison with the ESEM and FESEM data were carried out on living cyanobacteria; freshly collected cyan-bacterial communities and mats; and isolates of strains of known species of cyanobacteria, sulfate reducing bacteria, arachaea and other extremophiles grown in axenic culture at the Astrobiology Laboratory of the National Space Science and Technology Center (NSSTC). The visible light studies were carried out using an Olympus BH-2 and a ca. 1920 Leitz microscope with high-resolution Leitz apochromatic objectives and matched eyepieces. Visible light still images were recorded using a Sony 7.1 megapixel digital camera. Movies to documents motility of the extremophiles and disintegration of meteorite samples when exposed to liquid water and alcohol were recorded with a Sony HC-21 Video Camera.

The comparative visible light and electron microscopy study of living cyanobacteria was important to understand the differences in the appearance of known filamentous trichomic prokaryotes when viewed with different imaging methodologies. The ESEM and FESEM instruments usually provide images of the surface topology of microstructures. Consequently, it it is rare that the cells and other structures inside the external envelopes of most filamentous trichomic prokaryotes can be seen, even when filaments of living cyanobacteria are studied. In a few cases, where high voltages are used or the external sheath is electron transparent, it is possible to discern the cross-wall constrictions and thus discern information about the length and diameter of the cells that comprise the linear chain of cells known as trichome of the filamentous trichomic cyanobacteria and sulfur bacteria that often inhabit the anoxic regime of cyano-bacterial mats.

Since contamination by modern biological material was of great concern, the search for evidence of possible microfossils in meteorites was primarily restricted to the exclusive study of uncoated, freshly fractured interior samples of the meteorites. Visible light and ESEM/FESEM images and EDS spectra of the meteorite filaments and differentiated microstructures were compared with images and measured elemental compositions of the filaments, trichomes, sheaths, hormogonia, heterocysts and akinetes of known genera and species of living and recently dead cyanobacteria and other microbial extremophiles. Water in living samples appears as enhanced levels of oxygen. The Energy Dispersive X-ray Spectrometer (EDS) instruments are not capable of detecting hydrogen and they are not extremely sensitive nitrogen, which is reliably detected only at levels above $0.5 \%$ unless optimal conditions exist.

The characteristics of the ESEM and FESEM instruments used in this study are summarized below:

ElectroScan Corp. Environmental Scanning Electron Microscope (ESEM): The ESEM operates at a partial pressure of water vapor (10 Torr vacuum) in order to image uncoated, non-conductive samples without image degradation due to the effects of buildup of negative charge. The instrument operating voltage is $10 \mathrm{kV}$ to $30 \mathrm{kV}$ and it is capable of 
magnifications from $90 \mathrm{X}$ to $100,000 \mathrm{X}$. It is equipped with a 5 -axis stage and a Noran Instruments Energy Dispersive Spectrometer that can detect light elements ( $\mathrm{Z}>$ Boron).

Hitachi S-4100 Field Emission Gun Scanning Electron Microscope (FESEM): This instrument uses a cold cathode field emission electron gun and operates at accelerating voltages from $0.5 \mathrm{keV}$ to $30 \mathrm{keV}$. Operation at low voltages allows it to image uncoated meteorites and biological materials without the conductive coatings that are usually required to minimize the degradation effects of surface charging. The Hitachi S-4100 resolution limit is $1.5 \mathrm{~nm}$ (30 $\mathrm{keV}$; working distance $5 \mathrm{~mm}$ ) and the magnification range is $20 \mathrm{X}-300,000 \mathrm{X}$. It is equipped with both secondary electron (SED) and backscattered electron detectors (BSED). Images are recorded digitally (4Pi Analysis system) with up to 4096X4096 pixel resolution and 12 bit (4096 grays) digital image depth. This instrument is equipped with a KEVEX light element Energy Dispersive (EDS) X-ray detector (SiLi) with a minimum electron probe diameter of approximately 500 angstroms. Elemental abundance data can be measured at selected points or areas on the sample and $2 \mathrm{D}$ elemental $\mathrm{x}$-ray maps can be generated for the entire field of view. The

Hitachi S-3700N Variable Pressure Scanning Electron Microscope: The Hitachi S-3700N VP instrument has a Tungsten emitter electron gun and is capable of magnifications in the range of $5 \mathrm{X}$ to $300,000 \mathrm{X}$. It has both Secondary (SED) and Backscattered Electron Detectors (BSED). This instrument is equipped with a 4 Pi EDS system with a Silicon Drifted Silicon Detector capable of operating for $Z>$ Boron.

FEI Quanta 600 (FESEM and ESEM): The FEI Quanta 600 Field Emission Gun Scanning Electron Microscope is an extremely flexible instrument that has both low- and ESEM vacuum capability. Consequently it is capable of chargefree imaging and analysis of both non-conductive and hydrated biological specimens. The FEI Quanta 600 has a highresolution field emission SEM column optimized for high brightness and high current and is capable of producing simultaneous SED and BSED images. The detectors available include: Everhardt-Thornley SED; Low-Vacuum SED; and Solid-State BSED. The spatial resolutions obtainable at $30 \mathrm{kV}$ are: High vacuum: $0.8 \mathrm{~nm}$ (STEM); $3.0 \mathrm{~nm}$ (SED); $4.0 \mathrm{~nm}$ (BSED); Low vacuum: $3.0 \mathrm{~nm}$ (SED); $4.0 \mathrm{~nm}$ (BSED); ESEM mode: $3.0 \mathrm{~nm}$ (SED). At $3 \mathrm{kV}$ the resolution degrades to $12.0 \mathrm{~nm}$ (SED). The FEI Quanta 600FEG has a computer controlled 5-axis motorized stage with Peltier cooled stage. The 4096 X3536 pixel images are stored in either 8 bit or 16 bit TIFF files. The 4 Pi EDS system with a Lithium Drifted Silicon Detector can obtain EDS data on elemental abundances ( $Z>$ Boron) at selected points and can produce $2 \mathrm{D}$ elemental $\mathrm{x}$-ray maps for the entire field.

\subsection{Contamination Control}

Rigorous specimen handling, sample storage, and contamination control protocols were observed at all times in order to protect the meteorite samples from contamination during this study and insure the integrity of the research. The investigation was confined to an in-situ investigation of freshly fractured interior surfaces of meteorite samples. The exterior of the fusion crusts and old cracks and fissures in the meteorite samples were carefully avoided as they might have been contaminated by wind blown pollen or motile diatoms, bacteria or other modern biological contaminants. All containers and electron microscope stubs that were used were new and had never befor been employed for any studies. All of these containers and stubs, as well as all of the tweezers and tools used for the fracturing and handling the meteorite samples were cleaned with alcohol and flame sterilized with direct flame from a propane torch prior to use. This method was considered superior to sterilization by use of the autoclave, which would only kill but not totally destroy any contaminants of pollen grains or bacteria. Water, acids, liquids and other solvents, such as were used by the researchers who conducted previous studies to search for "organized elements". and other "acid-resistant microfossils" were strictly avoided. The use of liquids could introduce contaminants. Furthermore, as was discovered during the course of this research effort, many of the delicate filamentous microstructures found in the Orgueil CI1 carbonaceous meteorite were permineralized with magnesium sulfates with are highly soluble in water. Many of the forms encountered in the Murchison meteorite would be destroyed by acids. Consequently, the methods typically used to extract pollen grains, acritarchs, carbonized filaments, and other 'acid-resistant microfossils' from ancient terrestrial rocks would have destroyed many of the microstructures found during this study that have been interpreted as indigenous microfossils. The only exceptions to the strict ban on liquids were the few occasions in which carefully controlled and monitored experiments were conducted to evaluate the validity of the early reports that the Orgueil meteorite disintegrated immediately when it was exposed to liquid water or (more slowly) to alcohol. These experiments were carried out in the microscope vacuum chamber on pristine silicon wafers and to protect the 
samples from contaminants only sterile triply distilled water or pure Ethyl Alcohol was applied using a new sterile syringe configured with a 0.2 micron ultramicropore filter.

During all of the investigations, the freshly fractured meteorite samples were mounted on SEM stubs and great care was taken to insure that the freshly fractured interior surface was at the upper region of the sample. The stub was then inserted into the microscope vacuum chamber within minutes of the completion of sample preparation and the chamber evacuated. To protect the meteorite samples for future studies, the samples were placed in sealed containers as soon as they were removed from the microscope vacuum chamber and thereafter maintained in sealed vials in desiccator cabinets. To protect unused meteorite samples from contamination during long term storage, they were placed in sterile, glass containers purged with filtered dry nitrogen and sealed before being stored in a locked freezer and maintained at $-80^{\circ} \mathrm{C}$ at the NASA/NSSTC Astrobiology Laboratory.

\title{
2.2. Sample Coating
}

The Environmental and Field Emission Scanning Electron Microscopes were used to investigate uncoated samples of the meteorites. This approach was adopted since the putative nanofossils in ALH84001 had been ascribed to nanometer-sized coating artifacts. Clearly, the best way to avoid any possibility of coating artifacts was to study uncoated samples and therefore this method was for the meteorite research carried out at the NASA/Marshall Space Flight Center. However, it soon became obvious that many of the filaments forun in the Murchison and Orgueil meteorites were so large that they could not possibly be considered to results from coating artifacts. In some cases, where there was a desire to maximize spatial resolution and minimize charging effects if there was need to examine small features at very high magnifications, after initial observations and imaging of the specimen in an uncoated condition, some samples were coated with $3-5 \mathrm{~nm}$ of Osmium or $5 \mathrm{~nm}$ of Gold/Palladium. All of the images presented in this paper are of uncoated samples unless otherwise specified. The meteorite samples were typically studied using accelerating voltages of $11 \mathrm{keV}$ or $15 \mathrm{keV}$ to permit analysis of high $\mathrm{Z}$ elements (e.g. iron and nickel). To obtain better data on the low-X elements or when small filaments $(<1 \mu \mathrm{m})$ or thin electron transparent sheaths were studied, additional EDS data were taken at $5 \mathrm{keV}$ to minimize contributions by high-Z elements in the matrix near or under the filament.

During the past decade, a wide variety of samples have been studied at the NASA/NSSTC Astrobiology Laboratory. These include several different types of meteorites (carbonaceous, stony and nickel-iron, diogenites and SNC meteorites) and other astromaterials (Lunar dust collected during the NASA Apollo 11, 12, and 17 missions); terrestrial rocks (phosphorites, bauxites, shungites, oil shales, graphites, tufa, epsomite, cryptohalite. Hydrothermal vent chimney material, stromatolites, and banded iron formations), and living and fossil extremophiles (cyanobacteria, bacteria, archaea, diatoms, fungi, plants and other Eukarya) and macrofossils (Cambrian trilobites, Miocene fish and Pleistocene moss and wood). The research described in this paper is concerned with the study of several samples of the Murchison CM2 and the Orgueil CI1 carbonaceous meteorites provided by different Museums. Comparative images and EDS spectral data are also provided for living and dead cyanobacteria and bacteria from environmental samples, axenic cultures and herbarium material as well as fossilized cyanobacteria and filamentous prokaryotes in Proterozoic and Archaean rocks. These studies help to establish the morphologies and elemental compositions of ancient and modern biological materials obtained with the same instruments that were used to study the meteorites.

\subsection{Meteorites Investigated}

The following meteorites were studied at the NASA/Marshall Space Flight Center since 1997:

\author{
Carbonaceous Chondrites \\ CI1: Alais, Ivuna, Orgueil \\ C2 Ungrouped: Tagish Lake \\ CM2: Murchison, Mighei, Murray, Nogoya \\ CR3: Acfer 324 \\ CO3: Rainbow, Dar al Gani 749, Kainsaz \\ CV3: Allende and Efremovka \\ CK4: Karoonda
}

\section{Stony Chondrites, Achondrites and Iron Meteorites}




\author{
L4: Nikolskoye, Barratta \\ L/LL6: Holbrook \\ Diogenite: Tatahouhine \\ Iron: Henbury \\ Thiel Mountains and Patriot Hills, Antarctica: (TIL 99001 - 99019; PTH 99019) ${ }^{4}$
}

Large filamentous forms that exhibit distinctive morphological features and chemical differentiation and are in the proper size range for the fossilized remains of filamentous prokaryotes have been found only in the meteorites shown in Boldface. Similar forms have never been detected in the meteorites shown in italics during the studies carried out at NASA/MSFC. It should be pointed out that extremely small $(50-400 \mathrm{~nm}$ diameter spherical and rod-shaped) nanostructures have been observed in all of the meteorites studied. However, since these nanometric scale forms do not exhibit recognizable and unambiguously biological characteristics, they may are possibly be abiotic in origin. Since these tiny forms can not be undeniably shown to be biological, they have not been carefully studied during this research. The most exhaustive studies were devoted to the investigation of samples of the Murchison CM2 and the Orgueil CI1 meteorites. This is due to the fact that these stones have exhibited the most abundant and dramatic examples of well-preserved remains of large filaments that can be associated with known morphotypes of cyanobacteria. This may partly be due to the availability of excellent samples of these meteorites rather than their inherent content. For example, only minute fragments of the Alais, Tagish Lake, Mighei, and Kainsaz meteorites have been available for this study.

\title{
2.4. Meteorite Samples
}

The Murchison and Orgueil meteorite samples used in the study reported in this paper were:

\section{Murchison CM2 Carbonaceous Meteorite}

Victoria Museum, Melbourne, Australia

1 stone sample Abbington Farm (15 gm). Courtesy: Dr. William Birch

1 stone sample E4806 (9.5 gm). Courtesy: Dr. William Birch

1 stone sample E12291 (6 gm). Courtesy: Dr. William Birch

Musée Nationale d'Histoire Naturelle, Paris

Orgueil CI1 Carbonaceous Meteorite

1 stone sample S219: (0.5 gm). Courtesy: Dr. Claude Perron

2 stones: (0.6 gm \& $0.3 \mathrm{gm})$. Courtesy: Dr. Martine Rossignol-Strick

DuPont Meteorite Collection, Planetary Studies Foundation, Chicago

2 stones: (0.4 gm \& $0.1 \mathrm{gm})$. Courtesy: Dr. Paul Sipiera

Observations of the physical properties, fragility and EDS studies readily demonstrated that the Murchison meteorite matrix and embedded filaments are dramatically different from Orgueil meteorite matrix and filaments. The Orgueil meteorite is extremely fragile and readily disaggregated by liquid water or alcohol. The Orgueil filaments are permineralized mainly with epsomite or other magnesium sulfate minerals and encased within carbonized sheaths and empty high carbon envelopes are often found. The Murchison filaments are permineralized more with silicates and are never found infilled with epsomite. They often have high levels of Iron and detectable Nickel, which is not as abundant in Orgueil. Their morphological characteristics and EDS elemental compositions could never be confused with living or fossil cyanobacteria or the Orgueil forms.

\subsection{The Murchison CM2 Carbonaceous Meteorite}

The Murchison meteorite was observed to fall at 11:00 A.M, on September 28, 1969. The associated fireball was observed over a large region of Victoria, Australia and reported to be bright orange with a silvery rim and a conical tail just before it exploded into several pieces in the atmosphere. Loud detonations were heard and several hundred black stones fell within a 1.5 X $15 \mathrm{~km}$ scatter ellipse around the small town of Murchison, Australia ( $36^{\circ} 37^{\prime} \mathrm{S}$, 
$\left.145^{\circ} 14^{\prime} \mathrm{E}\right)$. The orientation of the scatter ellipse revealed the trajectory was from the southeast. Halliday and McIntosh ${ }^{5}$ used the reported observations of the fireball from nearby towns (Mildura and Sheparton) to compute orbital parameters for the likely parent body. They obtained $3 \mathrm{AU}$ for the aphelion and $0.992 \mathrm{AU}$ for perihelion. These results are consistent with peak concentrations of C-type asteroids. From these calculations they concluded the Murchison bolide overtook Earth at a low relative velocity $(\sim 13 \mathrm{~km} / \mathrm{s})$ and would have never come closer to the Sun than 1 AU.

In 1999, the author discussed the entry of the meteorite with Prof. John Lovering (the first scientist to extensively study Murchison) and several eyewitnesses to the fall who still resided in the town of Murchison. They reported the entire town and a large region around Murchison had a strong methyl alcohol aroma shortly after the stones fell. Several of the meteorites landed on the golf course. They bounced and rolled without penetrating the relatively soft ground indicating the terminal velocity of the stones was low. They also did not scorch the grass of a green, so much of their heat had been carried away by ablation. One stone penetrated a thin sheet metal roof of a shed and landed on dry hay without setting it on fire. It seems clear that this low-density meteorite slowed and was cooled as it traversed the atmosphere. Some of the stones were reported to have a coating of frost shortly after the fall, which was also reported for some Orgueil stones. These observations suggest that even though the thin outer fusion crust became very hot, the inner core must have remained very cold. Several pristine Murchison stones kept sealed in vials at the Victoria Museum still retain a strong sulfurous odor similar to asphalt or tar.

Seargent ${ }^{6}$ showed the Murchison orbit was similar to the periodic Comet Finlay and C-type Apollo asteroid 1979 VA and considered the possibility that the Murchison parent body might have been a comet. The aqueous alterations of minerals and indigenous organic volatiles suggest that the Murchison parent body must have approached the Sun near enough for indigenous water to have been in a liquid state, but not close enough for the volatiles to be stripped away. The cosmic ray exposure age of 800,000 years indicates Murchison may have formed as a large boulder "the cap of a pedestal" whose stem eroded away by sustained cometary activity. These results are consistent with observed indigenous volatiles and suggest that conditions on the parent body might have been very conducive to the growth of microorganisms such as the photosynthetic cyanobacteria and sulphur- and sulphate-reducing bacteria that are dominant in ice ecosystems and in sulfur-rich hypesaline environments on Earth.

The chemical properties and the mineralogy of the Murchison meteorite were first studied by Jaresowich ${ }^{7}$ and by Fuchs at al. ${ }^{8}$ The minerals of the Murchison meteorite are primarily $(68.6 \mathrm{wt} \%$ ) serpentines (antigorite, greenalite, and cronstedtite), and $15.8 \%$ chlorite. Murchison also contains other phyllosilicates, magnetites, sulfides, carbonates, graphites and insoluble organic matter similar to kerogen. The hydrated silicate and carbonate minerals of Murchison, together with the Oxygen isotopes establish that the alteration of these minerals occurred by aqueous geohemical processes within the parent body. Schulte and Schock ${ }^{9}$ used the mineral compositions and initial fluid compositions (based on cometary ice) and minimized the Gibbs free energy of closed chemical systems using stable and metastabel equilibrium constraints. They concluded that although many volatiles had been lost, the soluble organic compounds present in the Murchison meteorite were formed during the same interactions of rock and fluid water/rock ineractions that produced the observed aqueous alteration of the mineral phases.

\subsection{The Orgueil CI1 Carbonaceous Meteorite}

The Orgueil meteorite is probably the most extensively studied of all known meteorites. At 8:13 P.M on Saturday, May 14, 1864 a brilliant blue-white fireball illuminated a large region of Southern France. The bolide turned dull red in color as thunderous explosions and the sounds of cannon were heard lasting for two to three minutes) across the town of Montauban and the villages of Agen St. Clar, Nohic, and Orgueil. Over twent jet-black stones (some with mass exceeding $2 \mathrm{~kg}$.) fell in a $15-18 \mathrm{~km}$. east-west scatter ellipse. The villagers collected the stones (many still with complete fusion crusts) immediately after the fall and they documented this astonishing event in a series of letters ${ }^{10-14}$ many of which have been made available in English Translation by Nagy. ${ }^{15}$ When Orgueil first arrived it was like black clay. Leymeri ${ }^{16}$ cut a piece of the interior of one stone immediately after the fall and said: "The knife cut creates smooth and shiny surfaces which is an indication of a fine, paste-like matter." One stone landed in an attic and burned a farmer's hand ${ }^{17}$ as he touched it, and others were found a few hours later with a layer of frost coating the surface. Cloë ${ }^{18,19}$ and Pisani ${ }^{20}$ conducted detailed chemical analysis of some of the stones and found Orgueil to be soft, black and friable with $5.30 \%$ water soluble salts and observed that it rapidly disintegrates when exposed to liquid water. He described it as containing "ammonium and chlorine salt, potassium chloride; sodium chloride, magnesium sulphate, and calcium sulphate." Cloëz also found magnetite, silicic acid, $5.92 \%$ carbon, and 8$10 \%$ indigenous water of hydration liberated at $>200^{\circ} \mathrm{C}$. 
The Orgueil meteorite is a micro-regolith breccia, comprised of minute particulates cemented together by water soluble salts. In 1966, Boström and Frederickson ${ }^{21}$ showed that the Orgueil mineral associations provide clear and convincing evidence of extensive aqueous alteration on the parent body. Bunch and Chang ${ }^{21}$ reported that the dominant mineral of Orgueil was chlorite $(\sim 62.5 \%)(\mathrm{Fe}, \mathrm{Mg}, \mathrm{Al})_{6}(\mathrm{Si}, \mathrm{Al})_{4} \mathrm{O}_{10}(\mathrm{OH})_{8}$ of the Clay Phyllosilicate minerals group. The next most abundant components were the water-soluble evaporite mineral epsomite-( $\left.\mathrm{MgSO}_{4} \cdot 7 \mathrm{H}_{2} \mathrm{O}\right)$ (6.7\%) followed by $6 \%$ magnetite- $\mathrm{Fe}_{3} \mathrm{O}_{4} ; 4.6 \%$ troilite- $\mathrm{FeS} ; 2.9 \%$ gypsum- $\left(\mathrm{CaSO}_{4}: \mathrm{nH}_{2} \mathrm{O}\right) ; 2.8 \%$ breunnerite$(\mathrm{Fe}, \mathrm{Mg}) \mathrm{CO}_{3}$; and $0.5 \%$ limonite- $\mathrm{Fe}_{2} \mathrm{O}_{3} \cdot \mathrm{nH}_{2} \mathrm{O}$ ). The remaining $13.9 \%$ was found to be comprised of elemental Sulfur, and insoluble organic matter ("kerogen"). Other studies ${ }^{22,23}$ showed that Orgueil also contains several minor mineral species including: ammonium salts, anhydrite- $\mathrm{CaSO}_{4} ;$ calcite- $\mathrm{CaCO}_{3} ;$ serpentine- $\left(\mathrm{Mg}_{6} \mathrm{Si}_{4} \mathrm{O}_{10}(\mathrm{OH})_{8}+\mathrm{Fe}_{2} \mathrm{SiO}_{4}\right)$; trevorite- $\mathrm{NiFe}_{2} \mathrm{O}_{4} ;$ pyrrhotite-( $\left.\mathrm{Fe}, \mathrm{Ni}\right)_{0.9} \mathrm{~S}$; olivine- $\left(\mathrm{Mg}_{2} \mathrm{SiO}_{4}+\mathrm{Fe}_{2} \mathrm{SiO}_{4}\right)$; and pyroxene-( $\mathrm{Mg} \mathrm{Fe} \mathrm{Ca}$ silicates) ${ }^{22,23}$ Clayton ${ }^{24}$ found the Orgueil carbonates to have $\delta^{13} \mathrm{C} \sim+60 \%$ which clearly established them to be of extraterrestrial origin. The $\delta^{13} \mathrm{C}$ values of -7 to $-9 \%$ for the $\beta$-alanine in the Orgueil meteorite also fall outside the range of terrestrial values (typically -20 to $-30 \%$ ) and indicate an extraterrestrial origin of the Orgueil amino acid. In 2001, Ehrenfreund et al. ${ }^{25}$ suggested that the unique amino acid composition of Orgueil indicates a comet was the possible parent body.

\subsection{Biomarkers in the Murchison and Orgueil Meteorites}

The Murchison and Orgueil meteorites contains a host of complex organic compounds, biogeochemicals and fossil biomolecules that are considered indications of biological activity (i.e. biomarkers) when encountered in terrestrial rocks. These include weak bioindicators, that merely suggest biological activity may have occurred (e.g., racemic amino acids, carboxylic acids, aromatic, aliphatic and heterocyclic hydrocarbons, PAH's, amphiphilic components, sugars, etc. $)^{25-38}$ to strong chemical and morphological biomarkers for which there are no known abiotic formation mechanisms (e.g., amino acids with a strong enantiomeric excess, long chain fatty acids, and diagenetic degradation products of chlorophyll and evidence for recognizable microfossils. $)^{39-75}$

\section{RESULTS}

\subsection{Evidence for coccoidal colonies and pseudofilaments in the Murchison and Orgueil meteorites}

Even though spherical or coccoidal forms can be abiotic, they are also associated with a wide array of bacteria, cyanobacteria, archaea and algae. Clearly abiotic spheres in lunar dust studied can vary widely in size $(\sim 10$ $\mathrm{nm}$ to $>10 \mathrm{~mm}$ ), while known biological coccoids are typically restricted to much narrower size distributions $(\sim 200$ $\mathrm{nm}$ to $100 \mu \mathrm{m})$. The Orgueil and Murchison meteorites contain abundant coccoidal forms. They have all been found to lie within the very restricted size ranges associated with known morphotypes of cyanobacteria, bacteria, archaea and the smaller microalgae $(0.5 \mu \mathrm{m}$ to $20 \mu \mathrm{m}$ diameters). The meteorite forms also exhibit chemical differentiations indicative of biology as they are almost always found within carbonaceous envelopes or sheaths. The meteorite coccoidal forms are found singly and in complex colonies, assemblages, and pseudofilaments embedded in-situ in freshly fractured interior surfaces of the meteorites. High-resolution ESEM and FESEM images of these forms and Energy Dispersive X-ray Spectroscopy (EDS) analysis indicate their carbon-rich sheaths are usially infilled with minerals consistent with the meteorite matrix. Hence, they cannot easily be dismissed as modern microbial contaminants even though their morphological characteristics, size and size range are similar to known coccoidal and pseudofilamentous prokaryotes (archaea, bacteria) and algae. The meteorite forms are consistent with morphotypes of representatives of the Cyanobacterial Orders Chroococcales and Pleurocapsales.

Figure 1 provides ElectroScan ESEM and Hitachi FESEM (SED) images and EDS spectra of coccoidal forms found in freshly fractured interior surfaces of the Murchison CM2 and Orgueil CI1 meteorites. Figs. 1.a and b. are ESEM images of coccoidal forms found embedded in the Murchison meteorite sample provided by Dr. William Birch of the Victoria Museum, Melbourne, Australia and in the Orgueil sample S219 provided by Dr. Claude Perron from the meteorite collection of Musée Nationale d'Histoire Naturelle, Paris. The coccoid in Fig. 1.a. is a $3.5 \mu \mathrm{m}$ sphere with $\sim 200 \mathrm{~nm}$ diameter process at the top. The $9 \mu \mathrm{m}$ diameter coccoidal form in Fig. 1.b is enveloped in a thin $(\sim 150 \mathrm{~nm})$ partially broken away sheath-like structure $\mathbf{S}$ that EDS data indicates is carbon-rich when compared with the exposed interior mineral. Fig. 1.c. is a $15,000 \mathrm{X}$ ESEM image of a $5.2 \mu \mathrm{m}$ diameter coccoid in Orgueil that is enveloped within a $300 \mathrm{~nm}$ wrinkled carbonaceous sheath. Fig. 1.d. shows a $5.6 \mu \mathrm{m}$ diameter embedded coccoid from the Orgueil sample provided by Dr. Martine Rossignol-Strick. This 13,000X Hitachi FESEM image is marked (X) where the EDS spot spectrum Fig.1.e. was taken on the thick carbonaceous sheath. 

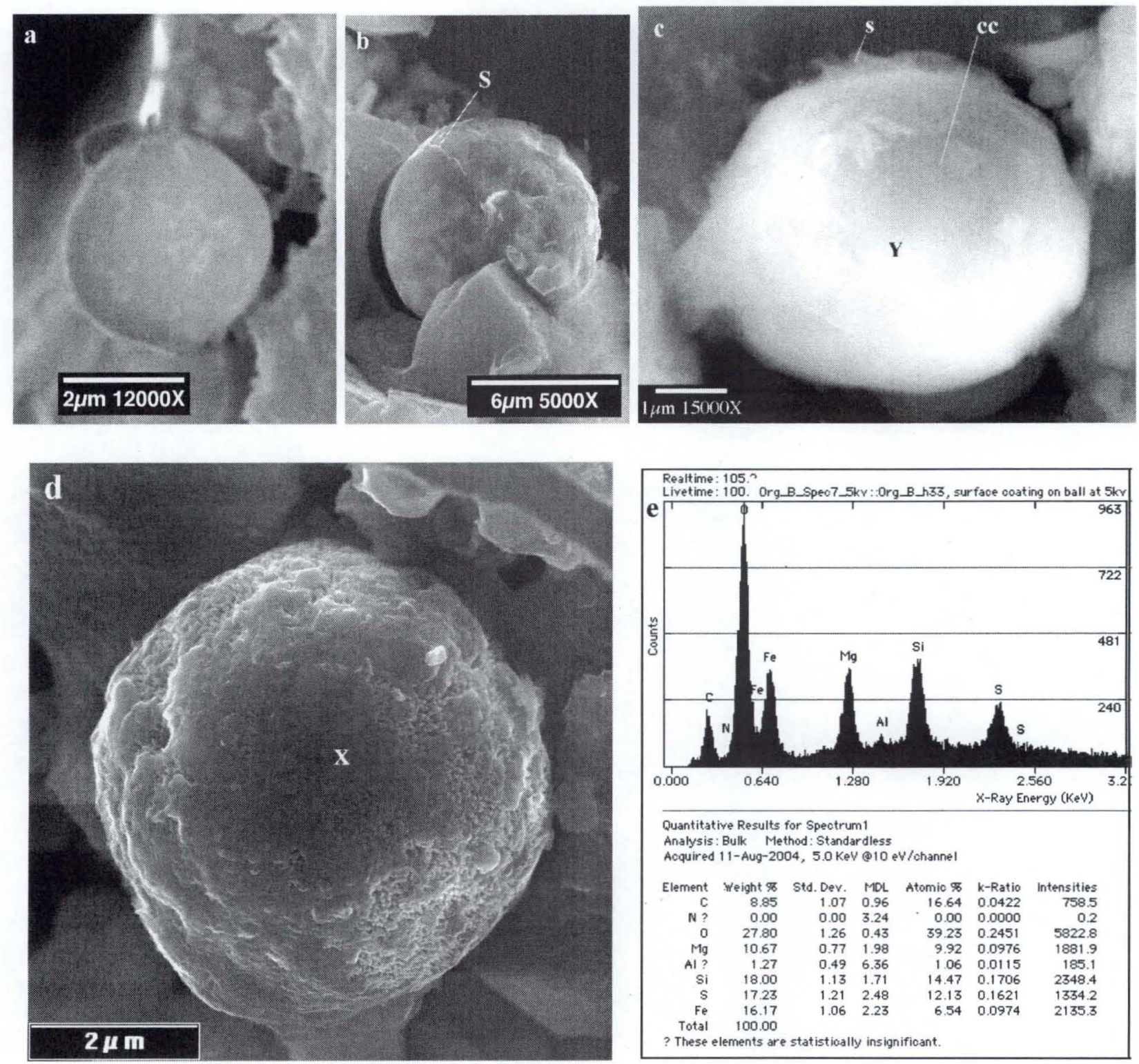

Figure 1. Embedded coccoidal forms in Murchison meteorite a. with narrow process or spike at top; b. with thin carbonaceous envelope or sheath; and coccoidal forms in Orgueil meteorite c. ESEM image $(15,000 \mathrm{X})$ of $5.2 \mu \mathrm{m}$ coccoid encased within a 300 $\mathrm{nm}$ thick carbonaceous envelope; $\mathbf{d}$. Hitachi FESEM image and e. EDS spectrum at $5 \mathrm{keV}$ measured at spot $\mathbf{X}$ on thick carbonaceous sheath of coccoidal form $-\mathrm{C} / \mathrm{N}>33 ; \mathrm{C} / \mathrm{S}=1.4$.

Figure 2.a. is a $10 \mathrm{kX}$ image of a coccoidal colony $\mathbf{C C}$ of irregular polygonal rounded forms with diameters ranging from $0.4 \mu \mathrm{m}$ to $1.5 \mu \mathrm{m}$. Each coccoid within this colony appears to be encased within its own thin capsule and the entire colony is surrounded by a thick (electron translucent @ $25 \mathrm{keV}$ ) carbonaceous ME mucilage envelope. Just above this colony there is a $2.6 \mu \mathrm{m}$ diameter laminated filament $\mathbf{F}$ with one apex tapering to a narrow terminus. Fig. 2.b. shows a $4500 \mathrm{X}$ image of a 9.4 diameter coccoid $\mathbf{C}$ beside an $8.6 \mu \mathrm{m}$ diameter hemispherical form $\mathbf{H}$. The hemispherical form is interpreted as indicating replication by binary fission and cleavage. These pseudofilaments are appear to be attached to the Orgueil meteorite rock substrate at their termini. They exhibit strong cross-wall constrictions and complex assemblages with many smaller forms of varying sizes in carbonaceous sheath. This $2000 \mathrm{X}$ Hitachi FESEM image shows several complex polarized filaments attached to the freshly fractured interior Orgueil surface. Fig. 2.d. is a Hitachi FESEM image of pseudofilaments of living Carnobacterium pleistocenium from the Fox Tunnel, Alaska with EDS data Fig. 2.e. showing a strong a nitrogen peak. ${ }^{79}$ 

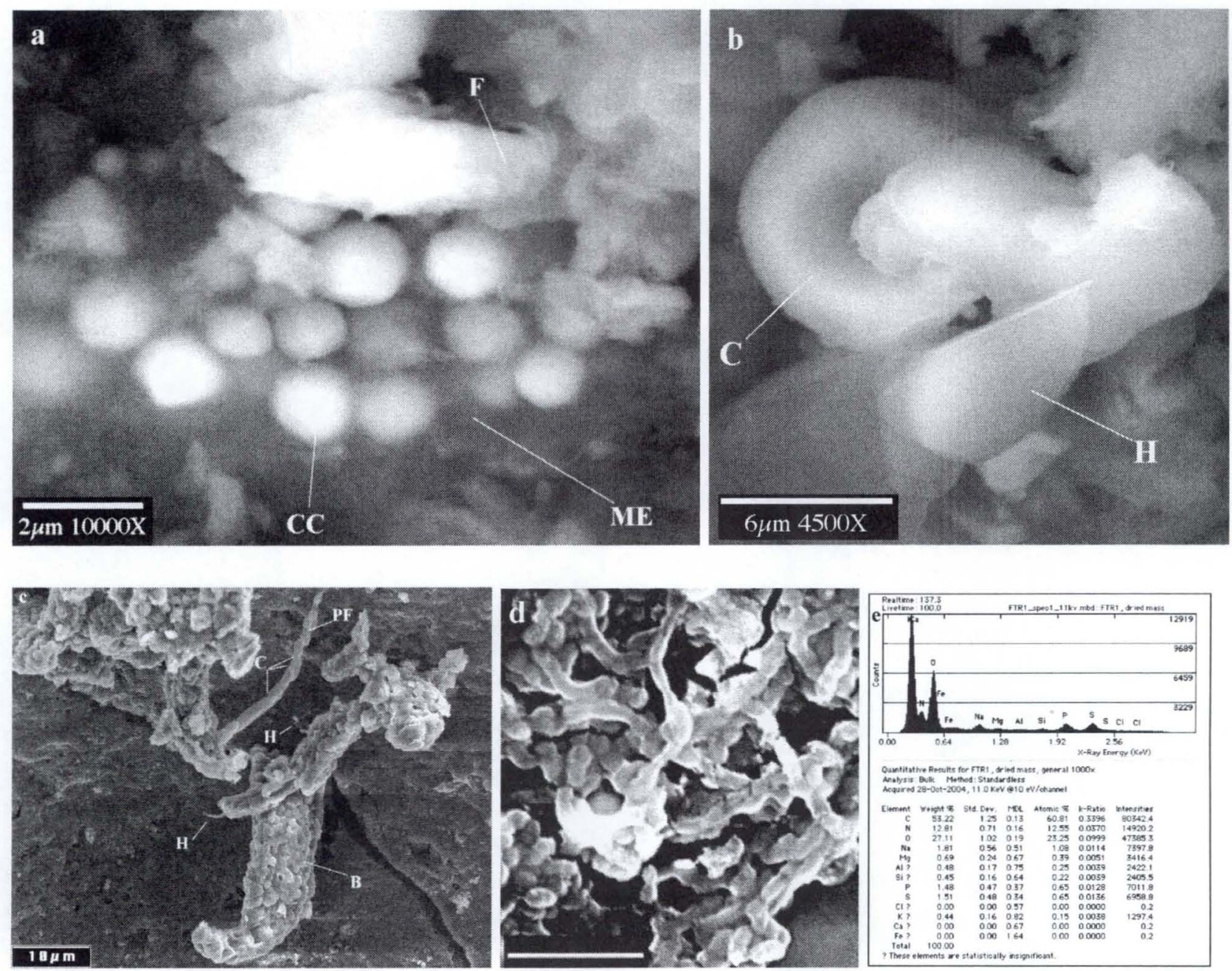

Figure 2.a. Coccoidal colony $\mathbf{C C}$ of irregular rounded forms in Orgueil in thick carbonaceous mucilage envelope $\mathbf{M E}$ with filament $\mathbf{F}$ and b. coccoidal $\mathbf{C}$ and hemispherical $\mathbf{H}$ forms in Orgueil meteorite. c. Hitachi FESEM images (3000X) mucilage encased round, polygonal and oblong cells similar to baeocytes in club shaped pseudofilaments with terminal hairs $\mathbf{H}$ in Orgueil meteorite as morphotypes of cyanobacterium Chamaesiphon rostaffinski; and d. Pseudofilaments of living Carnobacterium pleistocenium from Fox Tunnel, Alaska (bar $=10$ micron).

\subsection{Interpretation of coccoidal forms and pseudofilaments in the Murchison and Orgueil meteorites}

There are a number of genera of coccoidal and pseudo-filamentous cyanobacteria (Chroococcales \& Prochlorophytes; and Pleurocapsales) with cocci in the size range of the Murchison and Orgueil forms shown in Figures 1 and 2. The embedded forms found in the meteorites are composed primarily of the same suite of elements as the Murchison or Orgueil rock matrix (although their relative abundances are usually somewhat different from the nearby matrix) suggesting that these forms belong to the meteorite and are not post-arrival contaminants. Instead, the similar elements suggest that these forms were mineralized while fluids circulated through the parent body, whereas their relatively high carbon content is indicative of biogenicity. However, the almost total absence of detectable nitrogen provides strong evidence that these forms are not recent biological contaminants.

The individual cells that comprise these colonies and pseudofilaments are typically observed in the meteorites to be encased within electron transparent high carbon envelopes. In living cyanobacteria and bacteria, these indiviual cells are typically encased within their own individual slimy layer that is separate and distinct from the overall mucilaginous envelope that surrounds the colony. This non-cellular polysaccharide is referred to by various termscapsule, glycocalyx, mucilage, mucus, slime, etc. Modern cyanobacteria that form these coccoidal colonies include morphotypes of species of the genera Aphanocapsa and Gloeocapsa that are known to colonize subaerial, soil and 
aquatic habitats and grow on wet rocks and in thermal springs. These genera also have species that inhabit permafrost and are found as components of the cryptoendolithic communities of the McMurdo Dry Valleys of Antarctica. ${ }^{77}$ Several Aphanocapsa species have spherical or irregular coccoidal cells in the size range $0.4 \mu \mathrm{m}$ to $12 \mu \mathrm{m}$ diameter, and they typically exhibit a mucoid coating around each of the individual cells. Just as in the possible colonial assemblage of Fig. 2.a. found in the Orgueil meteorite, the living forms are known to secrete a gelatinous envelope that surrounds the entire colony. Members of this genus of cyanobacteria also reproduce by binary fission and cleavage giving rise to hemispherical daughter cells after cell division. Fig. 2.b. is an image of coccoidal and hemispherical forms in the Orgueil meteorite. This reproduction mechanism results in irregular cells of varying sizes (Fig. 2.a. and 2.b.) within the colony. ${ }^{78}$ Another cyanobacterial genus - Gloeocapsa (=Gleocapsa) - also has species that form mucilaginous aggregate colonies with spherical cells $(0.7-11 \mu \mathrm{m}$ diameter) each encased within thin sheaths. Gloeocapsa also has species that reproduce by binary fission and divide by cleavage producing hemispherical daughter cells after the cell division.

Scanning Electron Microscopy studies (even when applied to living forms) do not always allow many important distinguishing physical features (color, internal structures, thyllakoids, etc.) to be seen. Furthermore, fossilized microorganisms (except possibly some forms preserved in ice, salt, or amber) almost never contain information about physiological characteristics such as metabolism and nutrient requirements, reaction to gram stain, or phylogenetic information such as $16 \mathrm{~S}$ rRNA gene sequences. Since there are a large number of other genera and species of prokaryotic bacteria and archaea with spherical or irregular rounded polygonal cells that form gelatinous cell capsules and grow within mucilaginous enveloped colonies and it is simply not possible to identify the Orgueil forms with simple coccoidal morphologies more definitively than to interpret them as possible cyanobacteria or other unicellular and colonial prokaryotic bacteria or archaea although some of the larger forms could represent coccoidal algae (eukaryotes).

Figure 2.c. is an image of pseudofilamentous microstructures clearly attached to and embedded in the Orgueil meteorite rock substrate at their termini and which exhibit strong cross-wall constrictions. This pseudofilament exhibits a complex assemblage containing a large number of smaller forms of varying sizes that appear to be enveloped within that mucilaginous sheath that envelope the pseudofilaments. This $2000 \mathrm{X}$ Hitachi FESEM (SED) image shows several complex polarized filaments that appear to be epilithically attached to the freshly fractured interior surface of Orgueil. The form has numerous differentiated and irregular polygonal rounded coccoidal forms in a carbonaceous envelope. Pseudofilament PF ranges from $1.2-1.8 \mu \mathrm{m}$ in diameter. Cyanobacteria are known to form structures similar to the assemblage seen in B. Modern cyanobacterial morphotypes have similar coccoidal baeocyte-like forms enveloped within sporangia of mucoid material so as to produce curved club structures similar to the Orgueil form interpreted as a psuedofilament. Measurements indicate this form is $10 \mu \mathrm{m}$ wide where it enters or attaches to the Orgueil rock matrix. This pseudofilament curves and tapers to $3.4 \mu \mathrm{m}$ at the apex. The strong cross wall constrictions $\mathbf{C}$ are clearly seen and irregular polygonal rounded coccoidal forms of varying diameters are confined within the sheath in the upper portion of the pseudofilament. These small rounded polygonal forms are $\sim 1$ $\mu \mathrm{m}$ coccoids at the top of the filament and $\sim 5 \mu \mathrm{m}$ long ovoid forms seen near the bottom of the filament. Small hairlike structures $\mathbf{H}$ (with diameters ranging from $0.18-0.4 \mu \mathrm{m}$ ) protrude from the termini of two of the pseudofilaments of coccoidal clusters. These forms have size and configuration of the "terminal hairs" known in some cyanobacteria.

Fig. 2.d.is a FESEM image of a novel species of extremophile Carnobacterium pleistocenium str. FTR ${ }^{1}$ isolated by E. V. Pikuta at the NSSTC Astrobiology Laboratory from a 32,000 year old ice sample in the Fox Permafrost Tunnel of Alaska. ${ }^{79}$ The cells are linked together within mucilage to form pseudofilaments. The EDS elemental composition Fig. 2.e. of the dried mass of pseudofilaments shows a very strong carbon $(60.8 \%)$ and nitrogen ( $12.6 \%$ atomic) peaks but low Sulfur $(0.6 \%)$ giving ratios: $\mathrm{C} / \mathrm{N}=4.8 ; \mathrm{C} / \mathrm{S}=101$.

\subsection{Evidence of filamentous microfossils in the Murchison and Orgueil meteorites}

A low magnification $(1,000 \mathrm{kX})$ image of $\sim 120 \mu \mathrm{m}$ wide region of the Orgueil meteorite densely populated with several different types of embedded filaments and electron transparent sheaths is shown in Fig. 3.a. The many different embedded filaments microstructures exhibit a variety of complex morphological features that are well known in Oscillatorialean cyanobacteria. The external surface of filaments 1 and $\mathbf{2}$ can be seen to have irregular longitudinal striations suggesting the could contain multiple parallel oriented trichomes enclosed within a common homogeneous sheath. These filaments also appear to be attached to or physically embedded in the rock or clay substratum of the Orgueil meteorite rock matrix (i.e., epilithic or epipelic). The end of Filament 1 becomes slightly wider $(\sim 10 \mu \mathrm{m})$ where it joins the rock matrix and the striations suggest that the sheath may have enveloped four trichomes, each with a diameter of $\sim 2.5 \mu \mathrm{m}$. Filament 2 is larger $(\sim 20 \mu \mathrm{m}$ dia. $)$ and from the longitudinal striations $\sim 5$ trichomes are 
inferred indicating their diameters would be $\sim 4 \mu \mathrm{m}$. Measurements of the orthoganol marks faintly seen in Filament 2 , that may be interpreted as cross wall constrictions (C) suggest that the internal cells would have been $\sim 4 \mu \mathrm{m}$ in length and therefore roughly isodiametric. Consequently the inferred configuration of Filament $\mathbf{2}$ is that it consists of an ensheathed trichome bundle of parallel trichomes composed of isodiametric cells of $4 \mu \mathrm{m}$ diameter, consistent with species of cyanobacteria of the genus Microcoleus. Figure (3.d.)is a Hitachi FESEM image (500X) of an environmental assemblage of living Plectonema (Lyngbya) wollei filaments collected in May, 2004 by the author from Lake Guntersville, Alabama. This Hitachi FESEM image shows a flattened sheath with an emerged hormogonium showing faint cross-wall constrictions. The EDS elemental composition (Fig. 3.e.) of the hormogonium at spot X 1 shows a strong Nitrogen peak.
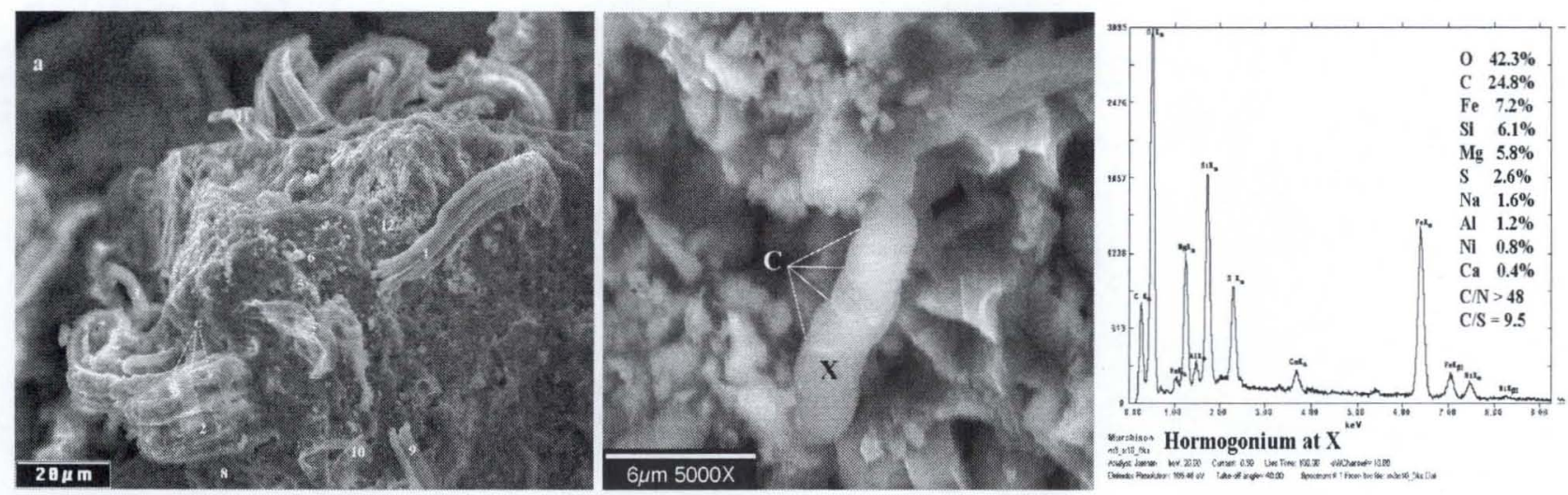

waraisen Hormogonium at $\mathrm{X}$

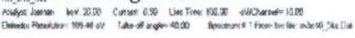
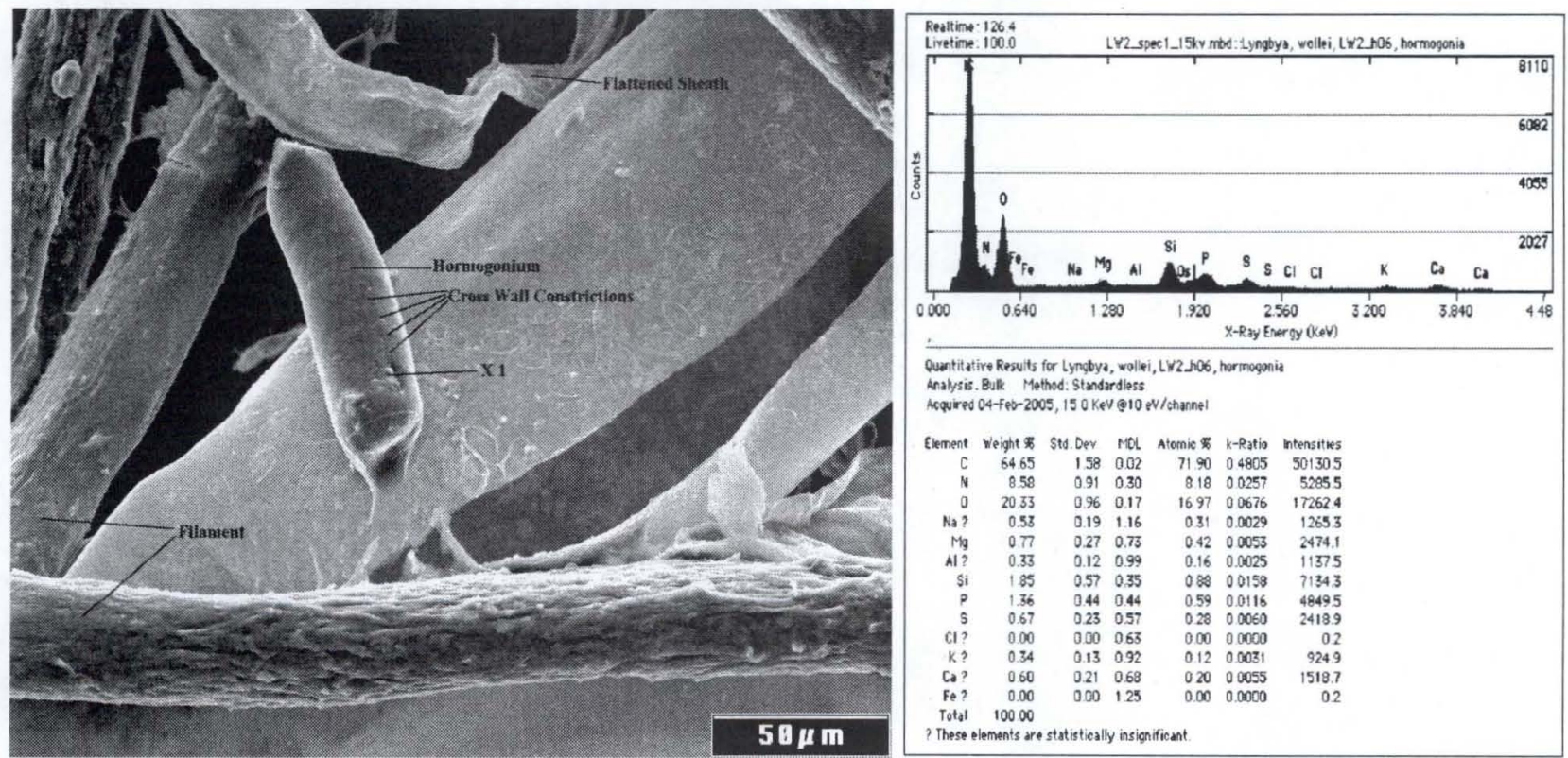

Figure 3.a. Hitachi FESEM (SED) image at $1000 \mathrm{X}$ of Orgueil sample showing multiple filaments and sheaths embedded in meteorite rock matrix. EDS spot spectral data provided in Table 1 are taken at positions where numbers are located. b. Orgueil form interpreted as emergent hormogonim of Nostocalean cyanobacteria with c. EDS spectral data at spot X; d. Hitachi FESEM image $(500 \mathrm{X})$ of living Plectonema (Lyngbya) wollei filaments with flattened sheath and emerged hormogonium showing faint cross-wall constrictions and e. EDS composition of living hormogonium at spot $\mathbf{X} \mathbf{1}$ showing strong nitrogen peak. 


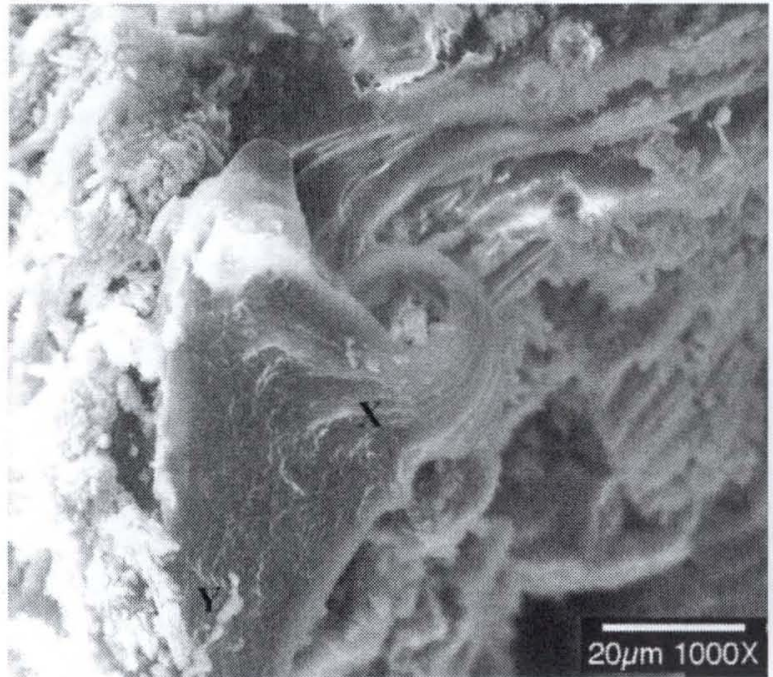

a.

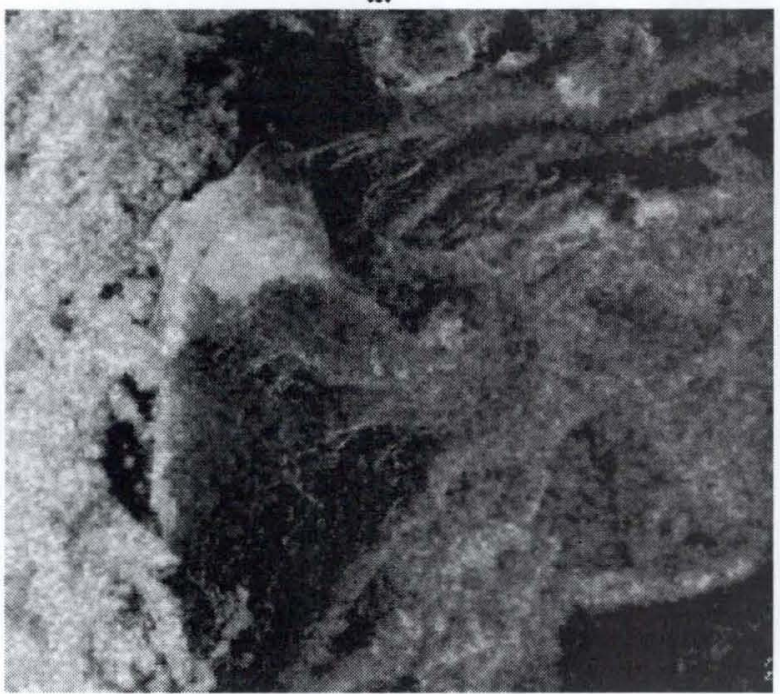

c.

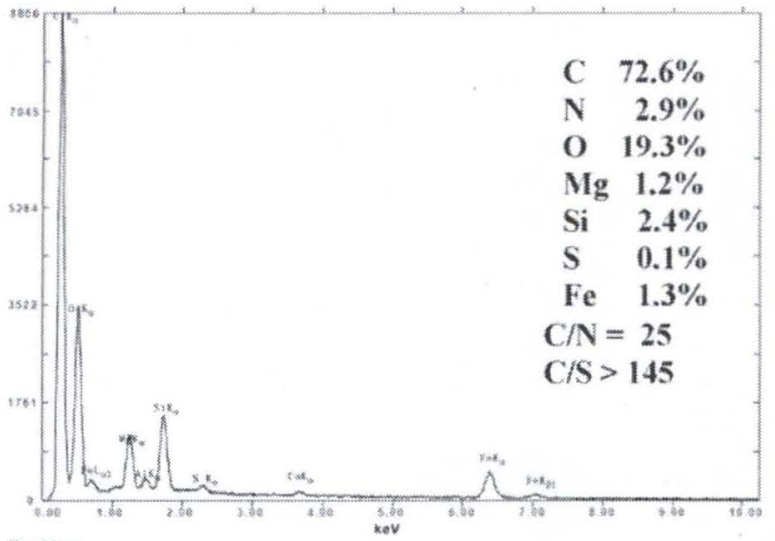

Murctises?

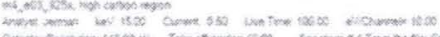

e.

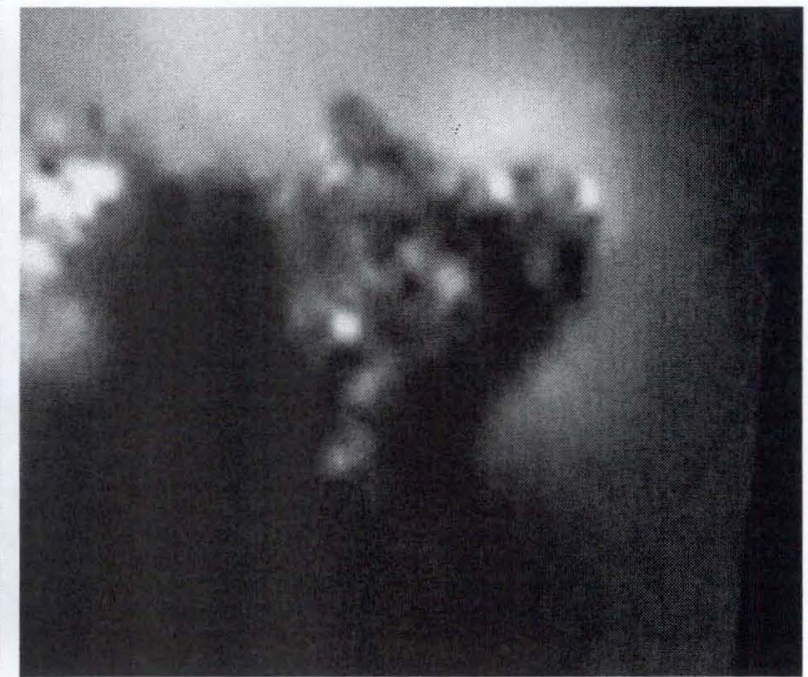

b.

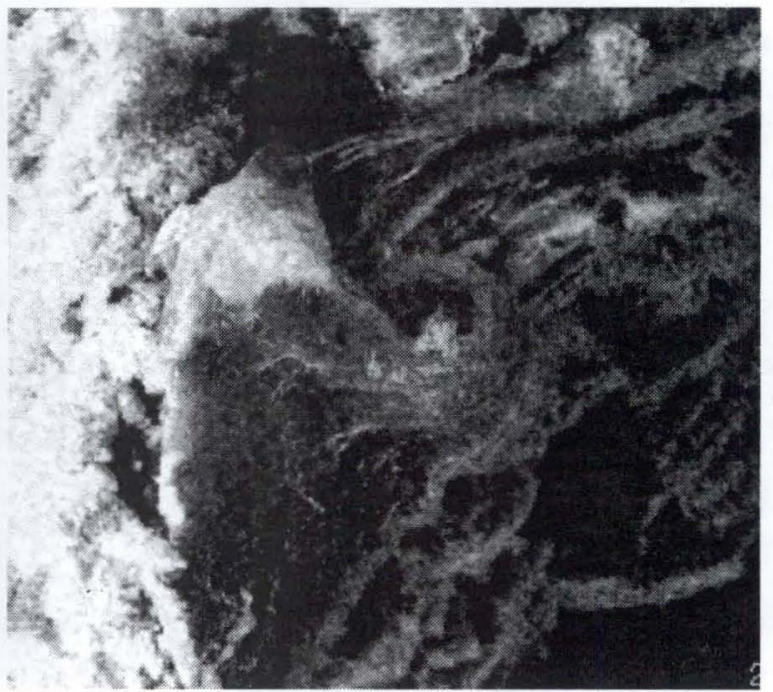

d.

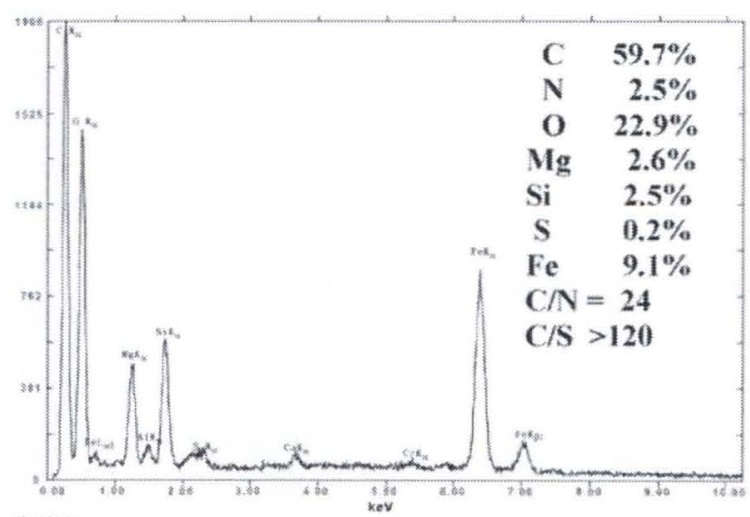

vastehises

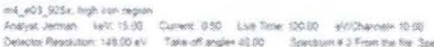

f.

Figure 4. Morphotypes of Microcoleus sp. and Phormidium sp. cyanobacterial filaments in Murchison as seen in a. $1000 \mathrm{X}$ FESEM image and Color images in b. Visible Light and 2D Elemental X-Ray Maps showing concentrations of c. Carbon (Red) \& Iron (Green); d. Carbon (Red), Silicon (Green) \& Oxygen (Blue) \& EDS data in e. High Carbon $\mathbf{X}$ and $\mathbf{f}$. High Iron $\mathbf{Y}$ spots. 


\section{CONCLUSIONS}

It is concluded that the Murchison CM2 and Orgueil CI1 carbonaceous meteorites contains complex embedded indigenous microstructures with complex morphological characteristics consistent with known morphotypes of modern cyanobacteria and the associated filamentous and coccoidal components of cyanobacterial mat communities. These forms are encountered in associations, consortia and colonial assemblages with sizes and size distributions of both the individual forms, the colonies and the filaments such of cyanobacteria and morphologically convergent sulfur bacteria and archaea. Although the coccoidal forms have relatively simple morphologies, they exhibit chemical differentiation and carbon-rich electron transparent envelopes as well as configuration into colonies and pseudofilaments with evidence of binary fision and baeocyte mechanisms of replication and other characteristics that provide strong supportive evidence in support of the hypothesis that they are biogenic rather than abiotic in origin. Both the Murchison and Orgueil meteorites contain large assemblage of isopolar and polarized filaments with extremely complex morphologies and differentiated cellular components. Many of these forms have recognizable features consistent with morphologies of many well-known genera and species of cyanobacteria and associated colonial assemblages of cyanobacterial mat communities. Ecologically consistent filamentous forms are found in close association in the Murchison and Orgueil meteorites such as are consistent with known associations found in Microcoleus mat communities and in terrestrial benthic and saline ecosystems. The majority of the filamentous forms in the meteorites appear to be benthic aquatic, epipelic, and epilithic forms rather than planktonic forms. These benthic microorganisms grow on Earth in mud or clay sediments; attached to rocks or present in benthic cyanobacterial mats that form at the interface between the liquid water and the substratum. Even though many terrestrial cyanobacterial species are resistant to desiccation, they are not known to carry out active growth and mat building when in a dried state. However, it is very well established that the Orgueil CI1 carbonaceous meteorite is a microregolith breccia comprised of minute particulates cemented together by water-soluble salts. Observations carried out in 1864 immediately after the Orgueil meteorite fell established that the meteorite stones are destroyed by exposure to liquid water. These results were confirmed by experiments carried out at NASA/NSSTC (Hoover, 2006b). Consequently, after the Orgueil meteorite arrived on Earth, none of the meteorite stones samples could have ever been submerged in pools of liquid water suitable needed to sustain the growth of large photoautotrophic cyanobacteria and required for the formation of benthic cyanobacterial mats. This observation strongly supports the conclusion that these coccoidal and filamentous forms are indigenous rather than recent biological contaminants. Furthermore, many of the Murchison and Orgueil coccoidal and filamentous microstructures exhibit $\mathrm{C} / \mathrm{N}$ and $\mathrm{C} / \mathrm{S}$ ratios that are dramatically different from living and old cyanobacterial filaments, mammoth and mummy hair and tissue. The biogenic element ratio data provides another line of evidence in support of the conclusion that these meteorites contain indigenous microfossils of the mineralized remains of prokaryotic microorganisms that grew on the parent bodies of the meteorites before they entered the atmosphere of Earth.

\section{ACKNOWLEDGEMENTS}

I am grateful for the Electron Microscopy support provided by Gregory Jerman and James Coston of the NASA Marshall Space Flight Center that made this research possible. I also want to thank Dr. Paul Sipiera and the James M. DuPont Meteorite Collection of the Planetary Studies Foundation, Chicago, Illinois, and Dr. Martine Rossignol-Strick and Dr. Claude Perron and the Meteorite Collection of the Musée Nationale d'Histoire de Paris for providing the Orgueil meteorite samples. I also thank Dr. Rosemarie Rippka of the Pasteur Institute (Paris), Academician Georgy Zavarzin and Dr. Ludmila M. Gerasimenko of the Institute of Microbiology, RAS (Moscow) and Dr. Sam van Landingham for many helpful discussions about the morphology and characteristics of cyanobacteria in natural environments and axenic cultures. I thank Dr. Ann St. Amand of Phycotech, Inc. Michigan for environmental samples of Calothrix and other living cyanobacteria and the late Dr. Walter van den Bergh of the Henri van Heurck Museum in Antwerp, Belgium for herbarium samples of early type algal material. I am grateful to Prof. A. Yu. Rozanov and Dr. M. M. Astafieva of the Institute of Paleontology, Russian Academy of Sciences, Moscow for helpful discussions concerning fossil cyanobacteria and samples of archaean rocks from Northern Karelia and Academician Erik Galimov for helpful discussions concerning meteorites and biological fractionation. I also acknowledge the funding support provided by the NASA/MSFC Center Director's Discretionary Fund; the NASA Astrobiology Institute and the NASA/JSC Center for Biomarkers in Astromaterials, which has made this research effort possible. 


\section{REFERENCES}

1. D. S. McKay, E. K. Gibson, Jr., K. L. Thomas-Keprta, H. Vali, C. S. Romanek, S. J. Clemett, X. D. F. Chillier, C. R. Maechling, and R. N. Zare, "Search for past life on Mars: Possible relic biogenic activity in Martian meteorite ALH84001." Science, 273, 924-930, 1996.

2. R. B. Hoover, "Meteorites, Microfossils and Exobiology," in Instruments, Methods, and Missions for the Investigation of Extraterrestrial Microorganisms, (R. B. Hoover, Ed.) Proc. SPIE, 3111, 115-136, 1997.

3. S. I. Zhmur, A. Yu. Rozanov, V. M. Gorlenko, "Lithified Remnants of Microorganisms in Carbonaceous Chondrites", Geochemistry International, 35, 58-60, 1997.

4. P. P. Sipiera, R. B. Hoover, G. A. Jerman, D. G. Butts, O. K. Garriott, W. Gruber, J. A. Lovell, and J. N. Pritzker. "A Preliminary Report on the Discovery of twenty Stone Meteorites from the Thiel Mountains and Patriot Hills, Antarctica," 63 Annual Meteoritical Society Meeting, 2000. http://www.lpi.usra.edu/meetings/metsoc2000/pdf/5021.pdf

5. I. A. Halliday and B. A. McIntosh, "Orbit of the Murchison meteorite", Meteoritics, 25, 339-340, 1990.

6. D. A. J. Seargent, "The Murchison Meteorite: Circumstances of its fall", Meteoritics, 25, 341-342, 1990.

7. Jarosewich, E., "Chemical analysis of the Murchison Meteorite," Meteoritics, 6, 49-52, 1971.

8. L. H. Fuchs, E. Olsen and K. Jensen, "Mineralogy and Mineral-Chemistry and composition of the Murchison (C2) meteorite. Smithsonian Contrib. Earth Sci.No. 10. 1-48, (1973).

9. Schulte, M. and Schock, E, "Coupled Organic Synthesis and Mineral Alteration on Meteorite parent Bodies", Lunar and Planetary Science XXIX, 1998. http://www.lpi.usra.edu/meetings/LPSC98/pdf/1456.pdf

10. Daubrée, A.. Note sur les meteorites tombées le 14 Mai aux environs d'Orgueil (Tarn-et-Garonne). Compt. Rend. Acad. Sci., Paris 58, 984-986, (1864.).

http://visualiseur.bnf.fr/ark:/12148/CadresFenetre?O-NUMM-3015\&M=tdm

11. Daubrée, A.., LeVerrier, M., Communication. Compt. Rend. Acad. Sci. Paris 58, 932-934, (1864). http:/visualiseur.bnf.fr/ark: $12148 /$ CadresFenetre?O=NUMM-3015\&M=tdm

12. de Puylaroque, M., Lettre du Juin 1 a M. Petit. Compt. Rend. Acad. Sci., Paris 58, 1070, (1864). http://visualiseur.bnf.fr/ark: $12148 / \mathrm{bpt6k} 3015 \mathrm{~d} /$ CadresFenetre?O=NUMM-3015\&M=tdm

13. d'Esparbés. M. Written communication with M. LeVerrier. Compt. Rend. Acad. Sci., 58, 934-935, (1864). http://visualiseur.bnf.fr/ark: $12148 /$ CadresFenetre? $\mathrm{O}=\mathrm{NUMM}-3015 \& \mathrm{M}=\mathrm{tdm}$

14. Jollois, M. Lettre de M. Jollois a M. LeVerrier, Blois, le 20 Mai 1864. Compt. Rend. Acad. Sci., Paris 58, $936-$ 937, (1864). http://visualiseur.bnf.fr/ark/12148/bpt6k3015d/CadresFenetre?O=NUMM-3015\&M=tdm

15. Nagy, B. 1975. Carbonaceous Meteorites. Elsevier Scientific Publishing Co., New York, pp. 1-747.

16. M. Leymeri, "Written communication with Mr. Daubree", Compt. Rend. Acad. Sci. 58, 1072, 1864.

17. S. Cloez, "Note sur la composition chimique de la pierre météorique d'Orgueil", Compt. Rend. Acad. Sci. 59, 37-40. 1864.

18. S. Cloez, "Analyse chimique de la pierre météorique d'Orgueil", Compt. Rend. Acad. Sci. 59, 37-40. 1864.

19. F. Pisani, "Etude chimique et analyse de l'aerolithe d'Orgueil", Compt. Rend. Acad. Sci. 59, 132-135, 1864.

20. K. Boström, and K. Frederickson, "Surrface Conditions of the Orgueil Meteorite Parent Body as Indicated by Mineral Associations." Smithsonian Misc. Coll. 151, pp. 1-39, (1966).

21. T. E. Bunch, and S. Chang, "Carbonaceous chondrites-II. Carbonaceous chondrite phyllosilicates and light element geochemistry as indicators of parent body processes and surface conditions." Geochim. Cosmochim. Acta 44, 1543-1577, (1980).

22. E. R. Dufresne and E. Anders, E. "On the Chemical Evolution of carbonaceous chondrites." Geochim. Cosmochim. Acta 26, 1085-1114, (1962).

23. K. Tomeoka and P. R. Buseck, "Matrix mineralogy of the Orgueil C1 carbonaceous chondrite." Geochim. Cosmochim. Acta 52, 1627-1640, (1988).

24. R. N. Clayton, "Carbon isotope abundances in meteoritic carbonates." Science, 140, 192-193, (1963).

25. P. Ehrenfreund, D. P. Glavin, O. Botta, G. Cooper and J. Bada, "Extraterrestrial amino acids in Orgueil and Ivuna: Tracing the parent body of CI type carbonaceous chondrites." Proc. Natl. Acad. Acad. Sci., 98, 2138-2141 (2001).

26. M. Berthelot, "Sur la Matiere charboneuse des meteorites." Compt. Rend. Acad. Sci., 67, 849, 1868.

27. K. A. Kvenvolden, J. G. Lawless, K. Pering, E. Peterson, J. Flores, C. Ponnamperuma, I. R. Kaplan and C. Moore, "Evidence for extraterrestrial amino acids and hydrocarbons in the Murchison meteorite, Nature 228, 923-926, 1970.

28. K. A. Kvenvolden, J. G. Lawless, and C. Ponnamperuma, "Non-protein amino acids in the Murchison meteorite", Proc. Natl. Acad. Sci. U.S.A. 68, 486-490, 1971.

29. S. Epstein, R. V. Krishnamurthy, J. R. Cronin, S. Pizarello, and G. U. Yuen, "Unusual stable isotope ratios in amino acid and carboxylic acid extracts from the Murchison meteorite", Nature 326, 477-479, 1987.

30. D. W. Nooner and J. Oro, "Organic Compounds in Meteorites, 1. Aliphatic Hydrocarbons." Geochim. Cosmochim. Acta 31, 1359-1394, 1967. 
31. R. Cronin and S. Pizzarello, "Aliphatic hydrocarbons of the Murchison meteorite", Geochim. Cosmochim. Acta 54, 2859$2868,1990$.

32. R. J. Olson, J. Oro, and A. Zlatkis, "Organic Compounds in Meteorites, 2. Aromatic Hydrocarbons." Geochim. Cosmochim. Acta 31, 1935-1948, 1967.

33. J. Oro, J. Gilbert, H. Lichstein, S. Wikstrom, and D. A. Flory, "Amino acids, aliphatic and aromatic hydrocarbons in the Murchison meteorite", Nature, 230, 105-106, 1971.

34. J. Oro, J. Gilbert, H. Lichstein, S. Wikstrom, and D. A. Flory, "Amino acids, aliphatic and aromatic hydrocarbons in the Murchison meteorite", Nature, 230, 105-106, 1971.

35. M. L. Studier, R. Hayatsu, and E. Anders, "Origin of organic matter in early solar system-V. Further studies of meteoritic hydrocarbons and a discussion of their origin", Geochim. Cosmochim. Acta 36, 189-215, 1972.

36. C. E. Folsomme. J. Lawless, M. Romiez, and C. Ponnamperuma, "Heterocyclic compounds indigenous to the Murchison meteorite", Nature 232, 108-109, 1971.

37. B. P. Basile, B. S. Middleditch, and J. Oro, "Polycyclic aromatic hydrocarbons in the Murchison meteorite", Organic Geochem. 5, 211-216, 1984.

38. Deamer, D.W. and R. Pashley. "Amphiphilic components of the Murchison carbonaceous chondrite: Surface properties and membrane formation." Orig. Life Evol. Biosphere 19, 21-38, 1989.

39. Cooper, G., Kimmich, N., Belisle, W., Sarinana, J., Katrina Brabham, K., Garrel, L. "Sugar-Related Organic Compounds in Carbonaceous Meteorites." Nature 414, 879-883, 2001.

40. M. Engel and B. Nagy, "Distribution and enantiomeric composition of amino acids in the Murchison meteorite," Nature 296, 837-840, 1982.

41. M. H. Engel and S. A. Macko, S.A., "Isotopic evidence for extraterrestrial non-racemic amino acids in the Murchison meteorite." Nature 389, 265-268, 1997.

42. M. H. Engel, V. E. Andrus, and S. A. Macko, "Amino Acids as Probes for Life's Origin in the Solar System." in Perspectives in Astrobiology, Vol. 366, NATO Science Series: Life and Behavioural Sciences (R. B. Hoover, R. Paepe, and A. Yu. Rozanov, eds.) IOS Press, Amsterdam, The Netherlands, pp. 25-37.

43. J. R. Cronin and S. Pizzarello, "Enantiomeric Excesses in Meteoritic Amino Acids", Science, 275, 951-955, 1997.

44. P. Ehrenfreund, D. P. Glavin, O. Botta, G. Cooper, and J. L. Bada, "Extraterrestrial amino acids in Orgueil and Ivuna: Tracing the parent body of CI type carbonaceous chondrites." Proc. Nat. Acad. Sci., 98, 2138-2141, 2001.

45. B. Nagy, and M. C. Bitz, "Long-chain fatty acids in the Orgueil meteorite." Arch. Biochem Biophys., 101, 240$248,1963$.

46. G. W. Hodgson, and B. L Baker, "Evidence for porphyrins in the Orgueil meteorite." Nature 202, 125-131, 1964.

47. G. W. Hodgson and B. Baker, "Porphyrins in meteorites: metal complexes in Orgueil, Murray, Cold Bokkeveld and Mokoia carbonaceous chondrites", Geochim, Cosmochim. Acta 33, 943-958, 1969.

48. M. Bitz, and B. Nagy, "Ozonolysis of "polymer type" material in coal, kerogen, and in the Orgueil meteorite: a preliminary report." Proc. Nat. Acad. Sci. 56, 1383-1390, 1966.

49. E. Gelpi and J. Oro, "Organic compounds in meteorites-IV. Gas chromatographic-mass spectrometric studies on the isoprenoids and other isomeric alkanes in carbonaceous chondrite s." Geochim. Cosmochim.Acta 34, 981-994, 1970.

50. R. Hayatsu, R., "Orgueil meteorite: organic nitrogen content s." Science 146, 1291-1293, 1964.

51. R. Hayatsu, M. H. Studier, L. P. Moore and E. Anders, "Purines and Triazines in the Murchison meteorite", Geochim. Cosmochim. Acta 39, 471-488, 1975.

52. C. E. Folsomme. J. Lawless, M. Romiez, and C. Ponnamperuma, "Heterocyclic compounds indigenous to the Murchison meteorite", Nature 232, 108-109, 1971.

53. L. L. Hua, K. Kobayashi, E. I. Ochiai, C. W. Gerke, K, O. Gerhardt, and C. Ponnamperuma, Identification and quantification of nucleic acid bases in carbonaceous chondrites, Origins of Life 16, 226-227, 1986.

54. P. G. Stoks, and A. W. Schwartz, "Nitrogen-heterocyclic compounds in meteorites: significance and mechanisms of formation," Geochim Cosmochim Acta 45, 563-569, 1981.

55. Y. V. Kissin, "Hydrocarbon components in carbonaceous meteorites." Geochim. Cosmochim. Acta 67, 1723-1735, 2003.

56. G. Claus and B. Nagy, "A microbiological examination of some carbonaceous chondrites, Nature 192, 594-596, 1961.

57. E. Anders and F. Fitch, "Search for organized elements in carbonaceous chondrites", Science 138, 1392-1399, 1962.

58. M. Rossignol-Strick and E. S. Barghoorn, "Extraterrestrial abiogenic organization of organic matter: The hollow spheres of the Orgueil meteorite", Space Life Sci. 3, 89-107, 1971.

59. R. Ross, "Panel Discussion: The identity of the 'organized elements", Ann. N. Y. Acad. Sci. 108, 608-609, 1963.

60. F. L. Staplin, "Microfossils from the Orgueil meteorite", Micropaleontol, 8, 343-347, 1962.

61. S. L. VanLandingham, "Evidence for microfossils in the Alais and Orgueil carbonaceous meteorite", Nature, 208, 947-948, 1965.

62. S. L. VanLandingham, C. N. Sun, and W. C. Tan, "Origin of round body structures in the Orgueil meteorite", Nature 216, 252253, 1967. 
63. W. C. Tan and S. L. VanLandingham, "Electron microscopy of biological-like structures in the Orgueil carbonaceous meteorite", Geophys. J. Roy. Astr. Soc, 12, 237-239, 1967.

64. P. Palik, "Further life-forms in the Orgueil meteorite", Nature 194, 1065, 1962.

65. W. Timofejev, "Lebensspuren in Meteoriten: Resultate einer microphytologischen analyse", Grana. Palynol. 4, 92-99, 1963.

66. H. C. Urey, "Biological Material in Meteorites: A Review", Science, 151, 157-166, 1966.

67. R. B. Hoover, "Meteorites, Microfossils and Exobiology," in Instruments, Methods, and Missions for the Investigation of Extraterrestrial Microorganisms, (R. B. Hoover, Ed.), Proc. SPIE, 3111, 115-136, 1997.

68. S. I. Zhmur, A. Yu. Rozanov, and V. M. Gorlenko, "Lithified Remnants of Microorganisms in Carbonaceous Chondrites," Geochemistry International, 35, 1, 58-60, 1997.

69. L. M. Gerasimenko, Richard B. Hoover, Alexei Yu. Rozanov, E. A. Zhegallo, and S. I. Zhmur, "Bacterial Paleontology and Studies of Carbonaceous Chondrites" Paleontological Journal, 33, 439-459, 1999.

70. R. B. Hoover and A. Yu. Rozanov, "Microfossils, Biominerals and Chemical Biomarkers in Meteorites." Instruments Methods and Missions for Astrobiology VI, (Hoover, R. B., Rozanov, A. Yu. and Lipps, J. H., Eds.), Proc. SPIE 4939, 1027, 2003.

71. R. B. Hoover, A. Rozanov, S. I. Zhmur and V. M. Gorlenko, "Further Evidence of Microfossils in Carbonaceous Chondrites" Instruments, Methods and Missions for Astrobiology, (R. B. Hoover, Ed.), Proc. SPIE 3441, 203-216, 1998.

72. A. Yu. Rozanov and R. B. Hoover, "Bacterial Paleontology and Astrobiology." Instruments Methods and Missions for Astrobiology IV, (Hoover, R. B., Levin, G. V., Paepe, R. and Rozanov, A. Yu., Eds.), Proc. SPIE 4495, 283-294, 2002.

73. R. B. Hoover, G. Jerman, A. Yu. Rozanov and P. C. W. Davies, "Biomarkers and Microfossils in the Murchison, Tagish Lake and Rainbow Meteorites." Instruments Methods and Missions for Astrobiology V, (Hoover, R. B., Rozanov, A. Yu. and Paepe, R. R., Eds.), Proc. SPIE 4859, 15-31, 2003.

74. Hoover, R. B., "Microfossils, biominerals, and chemical biomarkers in meteorites. in: Perspectives in Astrobiology, Vol. 366, NATO Science Series: Life and Behavioural Sciences, (R. B. Hoover, R. R. Paepe, and A. Yu. Rozanov, Eds.), IOS Press, Amsterdam, Netherlands, pp. 43-65. (2005).

75. Hoover, R. B., "Comets, asteroids, meteorites, and the origin of the Biosphere." in: Instruments, Methods and Missions for Astrobiology, $I X$ (R. B. Hoover, A. Yu. Rozanov, and G. V. Levin, Eds.), SPIE, 6309, 0J1-12. (2006).

76. Hoover, R. B. 2006b. Fossils of prokaryotic microorganisms in the Orgueil meteorite. in: Instruments, Methods and Missions for Astrobiology, $L X$ (R. B. Hoover, A. Yu. Rozanov, and G. V. Levin, Eds.), SPIE, 6309, 02 1$17,(2006)$.

77. de la Torre, J. R., Goebel, B. M., Friedmann, E. I. and Pace, N. R. "Microbial diversity of cryptoendolithic communities from the McMurdo Dry Valleys, Antarctica." Appl Environ Microbiol., 69, 3858-3867, (2003).

78. Wehr, J. D. and Sheath, R. G., (Eds.) Freshwater Algae of North America: Ecology and Classification. Academic Press, Amsterdam, pp. 1-918 (2003).

79. Pikuta, E. V., Marsic, D., Bej, A., Tang, J., Krader, P. and Hoover, R. B. Carnobacterium pleistocenium sp. nov., a novel psychrotolerant, facultative anaerobe isolated from permafrost of the Fox Tunnel in Alaska. Int. J. Syst. Evol. Microbiol., 55, 473 - 478. (2005). 